\title{
CENAS E CENÁRIOS DAS QUESTÕES SOCIOAMBIENTAIS: MEDIAÇÕES PELA FOTOGRAFIA
}

\author{
Manuella Teixeira Santos* \\ Erasmo Borges de Souza Filho** \\ Elinete Oliveira Raposo Ribeiro*** \\ Nadia Magalhães da Silva Freitas****
}

RESUMO: As questões socioambientais constituem-se foco de preocupação constante na contemporaneidade, inclusive para o ensino de ciências. Buscamos apreender as leituras de imagens fotográficas dos alunos de Licenciatura (Biologia e Física) sobre questões socioambientais da região metropolitana de Belém. Também propomo-nos a identificar e discutir as possibilidades de uso da fotografia no ensino de ciências, segundo a percepção dos alunos. Optamos pela abordagem qualitativa no contexto de uma pesquisa-ação. Ao fotografarem o contexto socioambiental local, os alunos se depararam com as transformações, no momento do ato fotográfico. Ao serem solicitados a escrever sobre o que fotografaram, os alunos foram construindo significados daquelas cenas e cenários, em um entrelaçamento de olhares crítico.

Palavras-chave: Questões socioambientais. Fotografia. Ensino de ciências.

\section{SCENES AND SCENERIES ABOUT SOCIO-ENVIRONMENTAL ISSUES: PHOTOGRAPHY MEDIATIONS}

ABSTRACT: Socio-environmental issues are a main constant concern in our contemporary time, including in the field of science education. We aimed to apprehend the readings of photographic images of students in undergraduate school (Physics and Biology) concerning socio-environmental issues in the metropolitan region of the city of Belém. We also propose to identify and discuss the possibilities of photographic use in science education, as perceived by the students. We chose a qualitative approach in the context of an action research. When photographing the local socio-environmental context, students faced the changes that were taken place there. When being requested to write about what they had photographed, the students were able to construct the meanings of those scenes and landscapes in a interlacing of critical views.

Keywords: Socio-environmental Issues. Photography. Science Education.

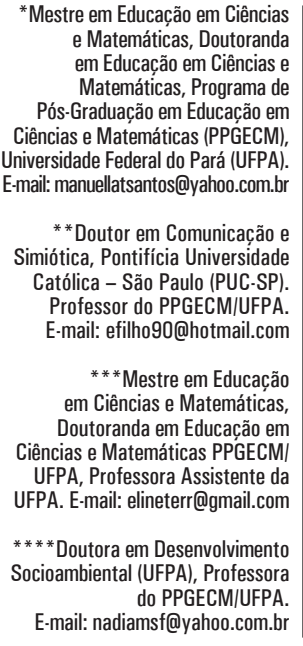

estre em Educação em Ciências e Matemáticas, Doutoranda em Educação em Ciências e

Matematicas, Programa de

Ciências e Matemáticas (PPǴECM), Universidade Federal do Pará (UFPA). E-mail: manuellatsantos@yahoo.com.br

* Doutor em Comunicacão Católica - São Paulo (PUC-SP). Professor do PPGECM/UFPA. em Ciencias e Matemáticas, iências e Matemáticas PPGECM

UFPA, Professora Assistente da UFPA. E-mail: elineterr@gmail.com

****Doutora em Desenvolvimento do PPGECMIUFPA.

E-mail: nadiamsf@yahoo.com.b 


\section{INTRODUÇÃO}

Os temas socioambientais têm sido foco de investigação de pesquisadores de diferentes áreas das ciências. E, para o ensino de ciências não é diferente, uma vez que se torna cada vez mais urgente a necessidade de educar para a constituição de outra relação dos seres humanos com o ambiente, inclusive com a adoção do pressuposto da sustentabilidade (BOFF, 2012; CARVALHO, 2011).

As questões socioambientais representam uma preocupação das sociedades contemporâneas. Em realidade, estamos experimentando um modelo de desenvolvimento que tem se mostrado ecologicamente predatório, socialmente perverso e politicamente injusto (ZIBETTI, 2006). Por isso, tais temas tornaram-se fundamentais nos diferentes setores da sociedade, a exemplo da educação, em geral, e do ensino de ciências, em particular.

A temática da sustentabilidade não se constitui um mantra da atualidade, embora seja “"...] repetida quase à exaustão em todo tipo de discurso relacionado com desenvolvimento (e crescimento) econômico" (CAVALCANTI, 2012, p. 35-36). Ao tratarmos de temas socioambientais nas nossas salas de aulas, buscamos atender ao imperativo de imprimir uma educação alicerçada na cidadania consciente da atual situação de emergência planetária, caracterizada por toda sorte de problemas estreitamente relacionados, tais como desemprego, fome, pobreza, contaminação e degradação dos ecossistemas, esgotamento de recursos naturais, mudanças climáticas, perda de diversidade biológica e cultural, entre outros (VILCHES; GIL-PÉREZ, 2007). Ao mesmo tempo, surge a necessidade de favorecer a adoção das necessárias medidas para a conformação de um futuro previsível.

Os Parâmetros Curriculares Nacionais (PCN) de Ciências Naturais indicam que "A questão ambiental, envolvendo aspectos econômicos, políticos, sociais e históricos, acarreta discussões sobre responsabilidades humanas voltadas ao bem-estar comum e ao desenvolvimento" (BRASIL, 1998a, p. 4142). Ademais, essa questão interessa a todas as áreas do ensino. Então, em função da crise ambiental vigente, faz-se necessário oferecer condições para que temas que transversalizem e dialoguem com o ensino de ciências, como as questões socioambientais e a sustentabilidade, estejam presentes mais efetivamente na sala de aula (VASCONCELOS; FREITAS, 2012).

Assim, a presente pesquisa buscou apreender as leituras dos alunos de Licenciatura (Biologia e Física), da Universidade Federal do Pará (UFPA), sobre as questões socioambientais vigentes, na região metropolitana de Belém, notadamente quanto aos aspectos críticos e reveladores dos elementos implicados nessas questões. A mediação desse processo se deu pela fotografia. Também buscamos perceber, junto aos alunos, a significação atribuída às possibilidades de uso da fotografia como estratégia de ensino de ciências. 


\section{O DESENHO DA PESQUISA}

$\mathrm{Na}$ realização da presente pesquisa, optamos pela abordagem qualitativa, fundamentados na possibilidade de compreensão da realidade e do mundo dos significados (MINAYO, 2008). Recorremos à pesquisa-ação, pois, assim como Franco (2005, p. 485), entendemos que "Se alguém opta por trabalhar com pesquisa-ação, por certo tem a convicção de que pesquisa e ação podem e devem caminhar juntas quando se pretende a transformação da prática”. Como estratégia de recolha de dados, desenvolvemos a oficina "A Fotografia no Ensino de Ciências", junto a dez alunos de graduação da UFPA (nove discentes do curso de Licenciatura Plena em Ciências Biológicas e um discente do curso de Licenciatura em Física). Para fins deste artigo, foram utilizados apenas os dados relativos a dois licenciandos (um de Física e outro de Biologia), considerando a consistência e a quantidade dos dados empíricos presentes nas leituras desses alunos.

Os instrumentos de coleta de dados constituíram-se dos registros fotográficos dos alunos e suas leituras, estas últimas mediatizadas pela produção textual. Além desses instrumentos, cada aluno fazia registros das suas impressões em diário de campo, a respeito da experiência de fotografar na perspectiva de apreensão das questões socioambientais. Assim, os dados relativos aos conhecimentos, aos entendimentos, e as interpretações, entre outros aspectos, foram organizados e analisados mediante análise textual discursiva. Segundo Moraes e Galiazzi (2011, p. 7), "[...] corresponde a uma metodologia de análise de dados e informações de natureza qualitativa com a finalidade de produzir novas compreensões sobre os fenômenos e discursos". Assim, as nossas análises se dirigiram aos textos produzidos no âmbito da própria pesquisa.

Podemos referir, ainda, que o "[...] conjunto de textos submetidos à análise costuma ser denominado o corpus [e importa numa] multiplicidade de vozes se manifestando sobre os fenômenos investigados" (MORAES, 2007, p. 87). Ademais, "É do corpus que são retiradas, durante a análise dos dados, as estruturas que serão utilizadas na elaboração de um novo texto, denominado de metatexto, este, possui a função de apresentar os resultados das análises" (FERREIRA, 2011, p. 50). Assim, escolhemos produzir metatextos referentes à apreensão das questões socioambientais, a partir da análise da produção textual referente às fotografias. Durante esse processo, decidimos identificar os alunos pelas iniciais de seus nomes para que fossem resguardadas suas identidades.

\section{A EMERGÊNCIA DAS QUESTÕES SOCIOAMBIENTAIS E O ENSINO DE CIÊNCIAS}

O Homo sapiens continua a fazer uso dos recursos disponíveis no único planeta conhecido (pelo menos até hoje) capaz de oferecer condições de existência para sua espécie e para as demais. Assim, em decorrência de um modelo de desenvolvimento pautado na premissa do inesgotável e da irracionalidade na 
exploração dos recursos naturais, no final do século XX a humanidade começou a se perceber imersa em graves problemas de ordem econômica, social e ambiental (FERREIRA, 2011; LEFF, 2002; SANTANA, 2008; UHMANN, 2013). As preocupações com esses problemas eclodiram quando a humanidade se viu diante de uma crise sem precedentes.

O cenário dessa crise "[...] foi montado a partir da crença que a industrialização seria uma panaceia, pois era entendida como sinônimo de desenvolvimento e, com isso, a modernização da sociedade apareceria como consequência" (FERREIRA, 2011, p. 19). Essa crise, decorrente também como parte dos avanços da ciência e da tecnologia, que até então eram vistos pela sociedade como a "salvação" para todos os males que a afligiam, foi se perpetuando e perdura até os dias atuais. Entretanto, mesmo diante de um cenário de crise

A incessante busca por desenvolvimento e bem-estar social faz com que a sociedade se torne, a cada dia, mais influenciada pelos avanços científico-tecnológicos. Esses avanços, muitas vezes, além de benefícios, vêm acompanhados por riscos e prejuízos, como, por exemplo, os relacionados às questões ambientais, à saúde e aos impactos na estrutura produtiva que geram desemprego (STRIEDER, 2008, p. 12).

Dessa forma, não podemos mais considerar a ciência como neutra e destituída de interesses, o que se aplica também à tecnologia gerada pelos conhecimentos científicos. Nesses termos, aumentam os constantes questionamentos feitos por uma parcela de pessoas preocupadas, de maneira especial, com os problemas ambientais e com as implicações decorrentes das atividades científicas e tecnológicas.

Em justaposição a esses problemas, pensou-se em um modelo de desenvolvimento no qual a sociedade passe a participar de forma responsável nas decisões. Trata-se do desenvolvimento sustentável, que “[...] não é somente um modismo intelectual que surge no final do milênio em consequência dos graves problemas ambientais que a humanidade está enfrentando" (FENZL, 1997, p. 1). Mesmo porque temos um estado atual de debates relativos ao desenvolvimento sustentável, certamente devido à assimilação do conceito em várias ambiências.

Acreditar ou não nessa possibilidade depende muito da leitura de mundo que cada um de nós fazemos a respeito de aspectos que podem contribuir para a garantia de um futuro previsível. E, nesse contexto, imputamos à educação um papel central na formação de cidadãos com sensibilidade socioambiental. Entendemos que o desenvolvimento de uma postura analítica, crítica e participativa nos problemas da sociedade é o resultado de uma formação atenta aos aspectos relativos à interação entre ciência, tecnologia e sociedade, bem como a difusão de valores, inclusive aqueles relacionados ao cuidado com o ambiente.

Assim, defendemos a ideia, no âmbito do ensino de ciências, da educação para o desenvolvimento sustentável, pois se trata de " [...] um esforço vital e eterno que desafia indivíduos, instituições e sociedades a olhar para o dia de amanhã como um dia que pertence a todos nós ou não pertencerá a ninguém" (UNESCO, 2005, p. 24). Nessa perspectiva, as questões socioambientais precisam ser tratadas 
em diferentes contextos de ensino e de aprendizagem de ciências, incorporando vários temas, conteúdos, estratégias, habilidades e competências em uma abordagem interdisciplinar. Assim considerando, identificamos a fotografia como um recurso que pode mediar a leitura e as discussões relativas ao (re)conhecimento da realidade socioambiental, notadamente no espaço de vivência dos alunos.

\section{A FOTOGRAFIA E SUA IMPORTÂNCIA NO ENSINO DE CIÊNCIAS E NA ABORDAGEM DAS QUESTÕES SOCIOAMBIENTAIS}

No contexto vivenciado atualmente, caracterizado pela atual emergência planetária, ponderamos que nos diversos espaços de formação, os mais variados recursos podem e devem ser empregados para viabilizar reflexões concernentes aos aspectos socioambientais, merecendo destaque a fotografia. Tal recurso tem, entre suas possibilidades, a capacidade de registrar vários aspectos do ambiente, dentre eles o social, o natural, o cultural. Assim, sua utilização como ferramenta didática poderá permitir o desenvolvimento de discussões que utilizem conhecimentos das mais diversificadas áreas do saber.

Embora a fotografia seja um recurso didático pouco utilizado (JUSTO, 2003), entendemos que ela favorece questionamentos a respeito, por exemplo, das causas das modificações nas paisagens, assim como a percepção de que todos nós estamos inseridos na problemática ambiental (FREIRE, 2001). Certamente tais indagações configuram-se aspectos de grande importância, pois a tomada de consciência é um dos primeiros passos para que queiramos mudar determinada situação.

A fotografia pode ser entendida como uma forma de contraposição ao imediatismo da sociedade atual, uma vez que ao nos depararmos com determinadas paisagens, poderemos elaborar comparações entre o passado, o presente e também perspectivar o futuro. Leite (1993, p. 23) afirma que os " [...] sinais de vida congelados numa fotografia são índices do mundo do passado que se busca compreender e podem se transformar em testemunho de uma realidade a ser construída". De fato, segundo nossa compreensão, a fotografia pode influenciar uma mudança de comportamento com relação ao ambiente.

A despeito de todos esses aspectos, Richter, Lopes e Freitas (2006, p. 9) mencionam que "Criou-se [...] a tradição de considerar-se o que está apresentado no livro didático como única forma possível de ensinar, consequentemente os professores têm dificuldade de pensar em conteúdos diferentes dos tradicionais". Assim, mesmo as figuras dos livros podendo auxiliar o entendimento de assuntos tratados em sala de aula, bem como o contexto socioambiental, elas não estão sendo aproveitadas da melhor forma, posto que não fomos preparados (professores) para lidar de maneira crítica com as imagens ou porque essas imagens não contextualizam, de fato, a realidade que se pretende problematizar.

A fotografia, segundo Mendes e Nobre (2008), nos permite observar o que muitas vezes não podemos ver. Kubrusly (2006) realça que algumas imagens, 
pela simples existência, impõem alguma providência. Por sua vez, a fotografia, se bem trabalhada no contexto educacional, pode trazer ganhos no que se refere à construção de conhecimento e à leitura crítica da realidade circundante, de modo que o aluno se torne questionador dessa mesma realidade e possa se constituir uma pessoa com sensibilidade socioambiental. Assim, a fotografia pode contribuir para a transformação social que se faz necessária na nossa sociedade.

\section{CENAS E CENÁRIOS SOB AS LENTES DAS QUESTÕES SOCIOAMBIENTAIS}

As discussões que se seguem dizem respeito às ponderações a respeito das apreensões e das leituras dos alunos participantes deste estudo, precisamente a respeito das fotografias trazidas por eles. A escolha das imagens a seguir apresentadas ocorreu devido a nossa compreensão de que ambas trazem em seu conteúdo uma espécie de complementaridade: "Pelos caminhos da civilização" representa os caminhos que a civilização trilhou até aqui, o que nos fez constatar que vivemos um processo de "Desenvolvimento sufocante", que não leva e nunca levou em consideração as consequências que poderia trazer para o ambiente e para a própria sociedade.

\section{PELOS CAMINHOS DA CIVILIZAÇÃO}

"Pelos caminhos da civilização" é o título conferido à Fotografia 1, feita pelo discente PM, a seguir apresentada. A imagem procura mostrar, nos seus aspectos gerais, as questões relacionadas à ocupação antrópica do ambiente e a forma como se estabelece a relação entre seres humanos e natureza. Nas palavras do aluno, a fotografia configura-se como "[...] uma analogia entre a ideia de caminho, como trilha evolutiva, com a ladeira que segue a diante”. A sua leitura revela preocupações com a complicada relação ser humano e natureza. Ao longo dos tempos, os seres humanos têm pilhado a natureza, ou seja, têm agido de forma predatória em relação ao meio ambiente.

Fotografia 1: Pelos caminhos da civilização.

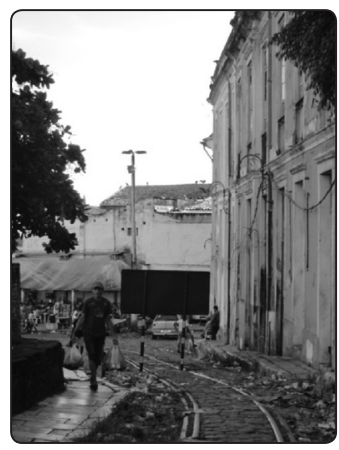


A partir da leitura do aluno, realizamos algumas releituras como as que se seguem: “[...] pensei de imediato na ocupação humana do ambiente natural, bem como na relação entre pessoas que acabam por construir (e desconstruir) os espaços [...]" (PM). Depreendemos que o aluno faz referência ao processo de ocupação dos espaços naturais e às formas como esse processo está afetando o ambiente. Nesse sentido, podemos dialogar com as observações de Silva et al. (2009, p. 2), a saber:

[...] o ambiente natural veio sendo drasticamente modificado pela ação humana. E o crescimento populacional, o desenvolvimento tecnológico, o acúmulo de resíduos são agentes que levam a uma interação desarmônica entre homem e biosfera, todos os organismos vivos que existem no planeta e seus habitats. $\mathrm{O}$ aumento da população exigiu grandes áreas para o cultivo, bem como a produção de bens de consumo que suprissem as necessidades que o homem adquiriu à medida que ocorriam modificações na sociedade. O conjunto desses fatores desencadeou os diversos problemas ambientais que podem ser percebidos atualmente, o que resultou em degradação ambiental.

Para corroborar com esse pensamento, Maricato (2001, p. 39) enfatiza que o processo de urbanização brasileiro se apresenta "[...] como uma máquina de produzir favelas e agredir o meio ambiente [...]”. Podemos observar que a ocupação do ambiente natural pelo homem, além de restringir os habitats das demais espécies e muitas vezes provocar a extinção de muitas delas, ocasiona, também, outros problemas, como a contaminação dos rios e do solo decorrentes, por exemplo, da deposição inadequada de resíduos sólidos e de esgotos domésticos tratados de maneira imprópria.

Assim, quando o aluno PM destaca que a "[...] ocupação humana do ambiente natural [...] acaba por construir (e desconstruir) os espaços [...]", entendemos que ele se refere aos inúmeros problemas que essa ocupação acarreta, não apenas para ele próprio, mas para todo o ambiente e toda a vida que o cerca. Esses problemas são os mais variados e têm diversificadas origens, resultantes, muitas vezes, da compreensão que a sociedade tem do ambiente e, consequentemente, da relação que estabelece com ele.

Assim, quando o discente menciona que o "[...] cotidiano urbano $[. .$. diz respeito ao modo do homem de tratar o ambiente [...]" (PM), entendemos que a forma como cada comunidade ou indivíduo se relaciona com o ambiente vai depender da maneira como eles o compreendem, como o enxergam. Nesses termos, são coerentes os questionamentos de Macedo et al. (2005, p. 2): "Mas, por que alguns indivíduos se preocupam em preservar a natureza, enquanto outros parecem simplesmente ignorá-la? Por que existe essa dicotomia?”. Assim, os próprios autores tentam responder às indagações:

Isso ocorre porque os indivíduos têm diversas percepções do meio no qual estão inseridos e, dessa forma, têm diferentes prioridades em relação ao meio, ou seja, cada sujeito dá uma importância diferente para o que sente ao seu redor e reage de maneira coerente (MACEDO et al., 2005, p. 2). 
É por isso que o sentimento das pessoas em relação a um determinado ambiente diverge, posto que depende dos seus valores. Para Macedo et al. (2005, p. 2), por meio da "[...] percepção ambiental são estabelecidas as relações de afetividade do indivíduo para com o ambiente. A partir da formação de laços afetivos positivos, pode acontecer a modificação dos valores ambientais atribuídos pelas pessoas", o que, em nossa opinião, é importante, já que vivemos um momento em que a "reaproximação" com o ambiente é imprescindível para que alcancemos um futuro previsível.

Notamos, também, a preocupação do educando em relação ao descarte inadequado do lixo: “[...] percebe-se que pelo caminho, há lixos e mais lixos [...]" (PM). Temos a considerar que a despeito da responsabilidade dos governos em relação a esse estado de coisas, as pessoas, individualmente e/ou coletivamente, têm sua cota-parte de responsabilidade em relação ao ambiente em que habitam. Nesses termos, acreditamos que a escola pode exercer papel importante no desenvolvimento de um olhar mais crítico dos alunos, bem como da comunidade escolar e seu entorno e, assim, difundir valores de cuidado com o ambiente (BOFF, 1999).

Ainda em relação à problemática do lixo, o aluno pondera: “[...] percebe-se que pelo caminho, há lixos e mais lixos, e subindo a ladeira, caminha um homem com suas compras. Não parecem os mesmo produtos, os que ele carrega e todos aqueles ao relento? Será que ele, ao usar o que foi comprado, vai despejá-los ao centro?" (PM). Com essas indagações, o educando reflete sobre o cotidiano urbano e como o homem da cidade relaciona-se com o ambiente. Corroborando com as ideias de PM, Mucelin e Bellini (2008, p. 114) afirmam que

As atividades cotidianas condicionam o morador urbano a observar determinados fragmentos do ambiente e não perceber situações com graves impactos ambientais condenáveis. Casos de agressões ambientais como poluição visual e disposição inadequada de lixo refletem hábitos cotidianos em que o observador é compelido a conceber tais situações como 'normais'.

Entendemos que é imprescindível o desenvolvimento efetivo de ações de Educação Ambiental que, segundo Tozoni-Reis (2002, p. 91), “[...] é mediadora da apropriação, pelos sujeitos, das qualidades e capacidades necessárias à ação transformadora responsável diante do ambiente em que vivem”, o que, certamente, contribuirá para que haja mudança nesse cenário.

Nesse ponto, destacamos que o consumo, por vezes exacerbado, coloca em cheque a premissa de que devemos buscar um desenvolvimento sustentável, o que podemos perceber como forte preocupação do aluno PM, expressa no seguinte trecho: "[...] toda uma sociedade, as pessoas compram, consomem e produzem seus rejeitos, no final, elas também sabem o que fazer com o lixo?”. Nesse aspecto, Mucelin e Bellini (2008) trazem a ideia de "cultura de consumo" e também de "hábitos de disposição final inadequados de lixo", o que nos leva a 
elaborar alguns questionamentos, a saber: como podemos continuar consumindo desenfreadamente sem julgarmos as consequências dessas ações? Como podemos compactuar com a "cultura do consumo"? Tais questões precisam permear o ensino de ciências no tratamento das questões e dos desafios ambientais contemporâneos (BRASIL, 1997a; 1998b; 2001).

É bem verdade que o consumo faz parte das atividades humanas, sendo ele, inclusive, indispensável nas sociedades capitalistas. Entretanto, a partir do momento em que as sociedades não se preocupam em discernir até que ponto esse consumo é necessário, elas passam a se caracterizar como sociedades consumistas. Nesse cenário, as pessoas não fazem reflexões no que tange aos impactos de suas ações a curto, médio e longo prazos e ao agravamento dos problemas socioambientais.

O aluno nos convida a pensar sobre isso ao mencionar que "[...] a civilização caminhou para o agora, o capitalismo nos instruiu desde crianças a querer mais e mais" (PM). É exatamente isso o que está acontecendo com uma enorme parcela da população que se encontra "embriagada" pelas possibilidades do consumo. Assim, podemos observar que "Transitoriedade, transformação, consumo, imediatismo, ansiedade, adição são elementos extremamente presentes na dinâmica da sociedade atual [...]” (BENEDETTTI; BÁRCARO, 2008, p. 13).

É interessante perceber quando o discente nos incita à seguinte reflexão: "É hora de tentar ser diferente, ou será que é tarde demais? Vamos procurar mudar?" (PM). Com essas provocações, nos voltamos para uma das poucas, talvez a única, opções [na visão dos mais radicais] para sanar os problemas relacionados às questões socioambientais, ou seja, uma mudança na maneira de ver e agir da humanidade, o repensar o futuro do planeta com uma ruptura no paradigma atual de desenvolvimento e em todo modo de ver o mundo, tal como apontam Espíndola e Arruda (2008, p. 7):

O novo paradigma para as ciências é aproveitar o meio ambiente, mas sem destruí-lo; é realizar a chamada conservação ambiental caracterizada pelo desenvolvimento econômico e pela utilização da natureza juntamente com a consciência e a prática de não degradá-la.

Isso seria, na prática, a realização de algo que talvez seja visto pela maioria das pessoas como utópico, mas que a sociedade não poderia perder de vista. Trata-se da questão da sustentabilidade, ou seja,

[...] um conceito que procura ligar vários de seus componentes: os sociais, ambientais, econômicos e os culturais. Esses componentes podem ser agregados pela ideia da sustentabilidade, vista como a busca pela qualidade de vida das atuais e das futuras gerações de todas as espécies que hoje dividem conosco o planeta. É preciso que a espécie humana contenha suas ambições e aceite os limites ambientais que são colocados com o intuito de preservar a qualidade de vida das outras espécies (DAL SOGLIO, 2009, p. 18). 
Dessa forma, depreendemos que o título "Pelos caminhos da civilização", atribuído à fotografia, é coerente com o atual estágio da civilização - diante de todo o percurso realizado pela humanidade, desde seus primórdios até o atual grau de avanço da ciência e da tecnologia, temos a exploração e a degradação de recursos naturais - processo predatório, uma marca da atual sociedade capitalista.

As contribuições do uso da fotografia no ensino de ciências, segundo PM, dizem respeito, por exemplo, ao prazer no desenvolvimento desse tipo de atividade, ao considerarmos a seguinte fala: "Com uma câmera em mãos, senti prazer em me empenhar para buscar pontos de vista singulares que remetessem a temática socioambiental, proposta da oficina. Tirar fotografias [...] é sempre uma experiência inédita em todas as suas dimensões, seja na frente ou atrás das lentes" (PM). Em relação ao prazer de fotografar, Costa (1999, p. 5) afirma que "Quem fotografa por prazer vê o mundo diferente, além de fazer um delicioso exercício de criatividade". Ademais, na perspectiva de trabalhar com o uso de fotografias no ensino de ciências, Wunder e Laganá (2005, p. 144) observa o seguinte:

Essa oportunidade foi importante para que eu buscasse [...] a troca que permitisse transcender o uso de fotografias do ensino específico de Ciências, percebendo nas imagens qualidades que se estendem para a produção dos conhecimentos em geral.

Ainda em relação à possibilidade de discussões das imagens no ensino, Martelli (2003, p. 20-21) destaca que

\begin{abstract}
A interpretação de imagens (fotos, gravuras [...]) é uma importante atividade que pode ser realizada com alunos de qualquer idade com: a identificação do que está presente, e mais importante, do que está ausente nestas imagens, aprendendo a ver e treinando o olhar crítico, a capacidade de observação e interpretação e, muitas vezes identificando além dos próprios fatos.
\end{abstract}

Entendemos que a fotografia, para além do ato prazeroso, cumpre com o papel de revelar, por exemplo, as questões socioambientais do nosso tempo, contribuindo para a formação crítica dos sujeitos.

\title{
DESENVOLVIMENTO SUFOCANTE
}

A Fotografia 2, abaixo apresentada, trazida pelo discente TG, procura retratar a contraditória situação "desenvolvimento e degradação ambiental". A leitura do texto, a seguir mostrado, já nos revela essa preocupação. É bem verdade que os modelos de desenvolvimento com ênfase no aspecto econômico e a naturalização dos problemas socioambientais têm se mostrado ineficientes, uma vez que tais problemas, longe de serem resolvidos, vêm se agravando ainda mais. 
Fotografia 2: Desenvolvimento sufocante.

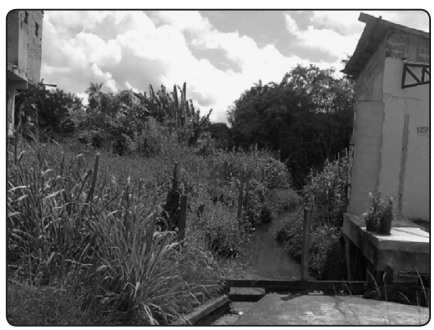

Vejamos, agora, algumas apreciações sobre a leitura da imagem realizada pelo aluno TG. Destacamos inicialmente o trecho: “o "desenvolvimento" estar sufocando o igarapé". Temos que nos referir ao destaque dado pelo aluno ao termo desenvolvimento, já que, ao colocá-lo entre aspas, põe em dúvida o processo que gera passivos ambientais, ou seja, a degradação do igarapé. De fato, o desenvolvimento deve configurar-se como ambientalmente prudente (SACHS, 2001) e comprometer-se com o cuidado do planeta Terra (BOFF, 2012), entre outros aspectos.

Outro trecho destacado observa que "[...] não houve preocupação com o futuro do igarapé [...] fazendo com que ele perdesse a vida paulatinamente [...]" (TG), o que nos faz lembrar a própria definição de desenvolvimento sustentável que preconiza a salvaguarda do uso-fruto dos recursos naturais para as gerações futuras (COMISSÃO, 1991). Na sequência, o aluno TG indaga “[...] este é o preço que temos que pagar pelo desenvolvimento?". Certamente, a resposta deveria ser negativa. Entretanto, a sociedade contemporânea, marcadamente capitalista, centraliza-se na disposição de utilização dos recursos naturais como se eles fossem infinitos.

Os debates, frutos das grandes conferências e encontros das Nações Unidas, a partir da década de 1970, e, principalmente, das análises constantes no Relatório de Meadows, publicizaram as questões prospectivas do mito do crescimento econômico infinito, a partir de uma base de recursos naturais finitos e vulneráveis à expansão capitalista (LIMA, 2009). Como ressalta Vecchiatti (2004, p. 90), vivenciou-se, na transição do século XX para o século XXI, o seguinte paradoxo: "Por um lado, o crescimento econômico e a transformação tecnológica sem precedentes, por outro, a dramática condição social de inúmeras pessoas, além de problemas ambientais assustadores".

Essa situação ainda perdura nos dias atuais. Por isso, o aluno TG faz um chamamento: "[...] temos que começar a agir rapidamente, pois, caso contrário, acabaremos com nosso planeta”. Cabe enfatizar que as questões socioambientais anunciadas (poluição, degradação dos ecossistemas, esgotamento de recursos naturais, mudanças climáticas, perda de diversidade biológica, desemprego, fome, pobreza, exclusão social, violência, etc.) são realidades fartamente documentadas (ESPÍNDOLA; ARRUDA, 2008; GUERRA; FANTINELLI, 2001; JACOBI, 2006; SILVA; TRAVASSOS, 2008; SOARES; NAVARRO; FERREIRA, 2004).

Por sua vez, entende-se que a responsabilidade desse estado de coisas não recai, apenas, nos governos, no mercado, nas lideranças, mas, também, nas 
pessoas, individualmente ou coletivamente. Mesmo porque suas ações, em grande medida, podem materializar-se, no âmbito de atuação de cada um, em ações em prol de um futuro de certezas (sobrevivência do planeta), inclusive, com maior implicação da cidadania. Trata-se da quota-parte de responsabilidade na conformação do desenvolvimento sustentável (VEIGA, 2008).

Quanto ao que observa o aluno TG, ou seja, "Muito se fala sobre desenvolvimento sustentável, entretanto, pouco se vê deste conceito sendo aplicado", podemos referir que a noção de desenvolvimento sustentável representa uma visão de futuro sobre a qual a humanidade precisa fundamentar seus objetivos de existência e coexistência (VEIGA, 2008). A transição da condição de insustentabilidade dos processos de desenvolvimento, para uma perspectiva de sustentabilidade, vai exigir da sociedade que a condicionalidade ambiental deva ser explicitada e respeitada a fim de se legar às gerações futuras um planeta habitável (BUARQUE, 1999).

O acelerado processo de urbanização das cidades brasileiras em associação com a pobreza, com as ocupações irregulares e com a falta de planejamento, entre outros aspectos, tem ocasionado inúmeros problemas socioambientais (JACOBI, 2006; SILVA; TRAVASSOS, 2008), o que contribui para a inadequada qualidade ambiental e de vida da sociedade. Então, tem sentido o que observa o aluno TG ao intitular sua fotografia de "Desenvolvimento sufocante", posto que tal desenvolvimento impede a continuidade de outros processos, ou seja, "[...] o crescimento [desenvolvimento] da cidade implicar na destruição do igarapé". Quanto às contribuições do uso da fotografia, o aluno TG afirma que "Esta experiência me serviu para avaliar questões socioambientais que ainda não havia avaliado" (TG). Nessa assertiva, podemos depreender que a experiência vivenciada por ele, possibilitada por intermédio do ato fotográfico, despertou-o para a avaliação das questões socioambientais.

De acordo com os PCN, "O tema transversal Meio Ambiente traz a discussão a respeito da relação entre os problemas ambientais e fatores econômicos, políticos, sociais e históricos" (BRASIL, 1997b, p. 35). Diz respeito à “[...] problemas que acarretam discussões sobre responsabilidades humanas voltadas ao bem-estar comum e ao desenvolvimento", sendo este "[...] sustentado, na perspectiva da reversão da crise socioambiental planetária” (BRASIL, 1997b, p. 35). Ademais, ainda de acordo com os PCN, "Sua discussão completa demanda fundamentação em diferentes campos de conhecimento [...] tanto as ciências humanas quanto as ciências naturais contribuem para a construção de seus conteúdos” (BRASIL, 1997b, p. 35).

Precisamos empreender no "[...] exercício da sensibilidade com base em um processo educativo [...] da valorização, do reconhecimento, da ação/transformação e da responsabilidade, uma relação ética e estética, de ordem sustentável e consciente, do sujeito com o meio" (TAVARES, BRANDÃO, SCHMIDT, 2009, p. 186). No âmbito do ensino de ciências, como professores, podemos empreender na internalização frequente das questões socioambientais, objetivando o fortalecimento de "[...] visões integradoras que, centradas no desenvolvimento, 
estimulam uma reflexão em torno da diversidade e da construção de sentidos nas relações indivíduos-natureza, dos riscos ambientais globais e locais e das relações ambiente-desenvolvimento" (JACOBI; MONTEIRO; FERNANDES, 2009, p. 18). Trabalhar o tema em questão permitiu ao aluno avaliar questões que antes não foram pensadas por ele.

O discente TG menciona, ainda, que "A primeira experiência que tive na oficina foi extremamente produtiva, pois pude fotografar lugares que frequentei quando criança e notar mudanças gritantes, principalmente quanto ao descaso da sociedade, quanto do poder público no que diz respeito à preservação do meio ambiente". Nesse trecho, apreendemos como pode ser significativa para o ensino de ciências a experiência de avaliar cenários reais. Isto porque tal avaliação permitiu ao discente tecer inúmeras reflexões críticas que estão além dos conteúdos disciplinares incomunicáveis.

Assim, a realização de trabalhos dessa natureza representa uma possibilidade para um ensino de ciências que se proponha renovador. Levar o aluno a conhecer sua realidade ambiente pode despertar algo diferente, ou seja, algo que o "toque" e o leve a tecer reflexões por si só. Ademais, quando o aluno percebe as modificações que estão ao seu redor e passa a pensar criticamente sobre esse estado de coisas, podemos avaliar que se efetivou uma aprendizagem significativa, notadamente na perspectiva da formação cidadã, tão desejável no ensino de ciência e na Educação Ambiental. Além disso, há o favorecimento da sensibilização para as questões socioambientais contemporâneas.

\section{CONSIDERAC̣̃̃ES FINAIS}

Os problemas socioambientais vivenciados pela humanidade consolidam-se como tema atual e relevante, notadamente no âmbito do ensino de ciências como tema transversal. Tais problemas aparecem como consequências imbricadas ao modo de produção dominante em nossa sociedade. Tratam-se das implicações do capitalismo, que acabaram se tornando sinônimo de desigualdade, devastação ambiental, injustiça social, etc.

Mediada pela utilização das fotografias como recurso importante no ensino de ciências, a presente pesquisa trouxe em seu cerne as apreensões das leituras de alunos da UFPA (Universidade Federal do Pará) a respeito das questões socioambientais vigentes na região metropolitana de Belém. Ademais, tratamos de suas possibilidades de uso para o ensino de ciências crítico, precisamente no campo ambiental. Também procuramos ponderar sobre as leituras realizadas por esses alunos, na melhor compreensão dessas questões. Por fim, buscamos avaliar as contribuições dessas leituras para a formação de professores/sujeitos com sensibilidade socioambiental.

Os discentes, ao se lançarem na busca das questões atinentes aos problemas socioambientais, "(re)direcionaram” a presente pesquisa, ou seja, nossa avaliação 
alcançou um nível "para além do esperado", do trivial; em sua edificação, o corriqueiro estagnou-se. Isto aconteceu porque, durante as construções analíticas, observamos a extrapolação dessas questões para outros campos do conhecimento, o "ir para além do que estamos vendo". E tudo isso foi plausível a partir dos olhares e das perspectivas oriundas das lentes fotográficas e críticas dos sujeitos do processo. Daí a importância do uso da fotografia em aulas de ciências, notadamente no tratamento de imagens que abranjam as questões socioambientais. $\mathrm{Na}$ mesma linha, podemos referir que a importância da imagem e da fotografia no ensino de ciências, e também para a educação como um todo, caminha para além de um mero componente ilustrativo.

Nossos sujeitos da pesquisa-ação, ao fotografarem alguns aspectos do contexto socioambiental local, depararam-se com transformações antes não percebidas, no instante do ato fotográfico. E, ao serem solicitados a escrever sobre o que fotografaram, eles foram construindo os significados daquelas cenas e cenários da região metropolitana de Belém. Dessa forma, depreendemos que trabalhar com fotografias não diz respeito apenas a usá-las como simples suporte para as aulas, mas propiciar que o aluno possa apreender os múltiplos contextos capturados pela imagem, em um entrelaçamento de olhares que se fez crítico.

No nosso entendimento, a fotografia se constitui ferramenta fundamental para o ensino de ciências, pois ela possibilita não somente enxergar a questão central de determinada imagem/situação, mas além dela, incorporando aspectos multidimensionais que caracterizam os objetos de estudos complexos, como as questões socioambientais. Ponderamos que no uso de fotografia construímos espaços de possibilidades, subjetividades, autoria, autonomia, conhecimentos, saberes e sensibilidades na leitura do mundo. Certamente, tais espaços constituem-se como perspectivas potencializadoras do processo de ensino e de aprendizagem.

Na mesma linha, podemos referir que a mediação fotográfica, no âmbito do ensino de ciências, apresenta a possibilidade de inquietar, provocar, transformar os modos de aprender e de ensinar, notadamente no que diz respeito às questões socioambientais, de forma não reducionista e asséptica, imprescindíveis ao desvelamento do mundo. As apreensões mais alargadas das questões socioambientais, associadas aos valores relacionados ao pressuposto da sustentabilidade, contribuem para a qualidade social do ensino de ciências. No conjunto, avaliamos que tais aspectos são consoantes com a necessidade de renovação do ensino de ciências.

\section{REFERÊNCIAS}

BENEDETTI, I. M. M.; BÁRCARO, F. A Cultura e o novo solo histórico: reflexões sobre nosso tempo. Saber Acadêmico, São Paulo, n. 6, p. 12-22, 2008.

BOFF, L. Saber cuidar: ética do humano - compaixão pela Terra. 16 ed. Petrópolis, RJ: Vozes, 1999. BOFF, L. Sustentabilidade: o que é - o que não é. Petrópolis, RJ: Vozes, 2012.

BRASIL. Secretaria de Educação Fundamental. Parâmetros Curriculares Nacionais: apresentação dos temas transversais, ética. Brasília: MEC/SEF, 1997a. 
BRASIL. Secretaria de Educação Fundamental. Parâmetros Curriculares Nacionais: Ciências Naturais (1 ${ }^{\mathrm{a}}$ a $4^{a}$ séries). Brasília: MEC/SEF, 1997b.

BRASIL. Secretaria de Educação Fundamental. Parâmetros Curriculares Nacionais: Ciências Naturais $\left(5^{\mathrm{a}}\right.$ a 8 a séries). Brasília: MEC/ SEF, 1998a.

BRASIL. Secretaria de Educação Fundamental. Parâmetros Curriculares Nacionais: meio ambiente: saúde. $3^{\text {a }}$ ed. Brasília: MEC/SEF, 2001.

BRASIL. Secretaria de Educação Fundamental. Parâmetros Curriculares Nacionais: terceiro e quarto ciclos: apresentação dos temas transversais. Brasília: MEC/SEF, 1998b.

BUARQUE, S. C. Metodologia de planejamento do desenvolvimento local e municipal sustentável. Brasília: Instituto Interamericano de Cooperação para a Agricultura, 1999.

CARVALHO, I. C. M. Educação ambiental: a formação do sujeito ecológico. São Paulo: Cortez, 2011.

CAVALCANTI, C. Sustentabilidade: mantra ou escolha moral? Uma abordagem ecológico-econômica. Estudos Avansados, São Paulo, v. 26, n. 74, p. 35-50, 2012.

COMISSÃO MUNDIAL SOBRE O MEIO AMBIENTE E DESENVOLVIMENTO. Nosso futuro comum. Rio de Janeiro: FGV, 1991.

COSTA, P. P. da. 160 anos de Fotografia. Revista Fotografia Popular. 1999. Disponível em: <http:// www.uel.br/pos/fotografia/wp-content/uploads/downs-uteis-160-anos-de-fotografia.pdf $>$. Acesso em: 29 ago. 2012.

DAL SOGLIO, F. A crise ambiental planetária, a agricultura e o desenvolvimento. In: DAL SOGLIO, F. (Org.). Agricultura e sustentabilidade. Porto Alegre: Editora da UFRGS, 2009. p. 13-32.

ESPÍNDOLA, M. A. J.; ARRUDA, D. de O. Desenvolvimento sustentável no modo de produção capitalista. Revista Visões, Macaé, Rio de Janeiro, v. 1, n. 4, p. 1-11, 2008.

FENZL, N. Estudo de Parâmetros capazes de dimensionar a sustentabilidade de um processo de desenvolvimento. In: XIMENES, T. (Org.). Perspectivas do Desenvolvimento sustentável. Uma contribuição para a Amazônia 21. Belém: Universidade Federal do Pará, Núcleo de Altos Estudos Amazônicos, 1997.

FERREIRA, D. T. Temas socioambientais para o ensino de Ciências Naturais. 2011. 138 f. Dissertação (Mestrado em Educação em Ciências e Matemáticas). Instituto de Educação Matemática e Científica, Universidade Federal do Pará, Belém, 2011.

FRANCO, M. A. S. Pedagogia da pesquisa-ação. Educação e Pesquisa, São Paulo, v. 31, n. 3, p. 483-502, 2005.

FREIRE, P. Conscientização: teoria e prática da libertação - Uma introdução ao pensamento de Paulo Freire. 3 ed. São Paulo: Centauro, 2001.

GUERRA, S. M. G.; FANTINELLI, J. T. A aproximação entre tecnologia e economia: os emergentes papéis da energia. Revista de Estudos Sociais, Cuiabá, Mato Grosso, n. 5, p. 33-58, 2001.

JACOBI, P. R. Impactos Sócio-Ambientais Urbanos na Região Metropolitana de São Paulo. Revista VeraCidade, Salvador, Bahia, ano 1, n. 1, p. 1-12, 2006.

JACOBI, P. R.; MONTEIRO, F.; FERNANDES, M. L. B. Educação e Sustentabilidade: caminhos e práticas para uma educação transformadora. São Paulo: Evoluir Cultural, 2009.

JUSTO, C. S. S. Os meninos fotógrafos e os educadores: viver na rua e no Projeto Casa. São Paulo: UNESP, 2003.

KUBRUSLY, C. A. O que é Fotografia. São Paulo: Brasiliense, 2006. (Coleção Primeiros Passos).

LEFF, E. Epistemologia Ambiental. 2 ed. São Paulo: Cortez, 2002.

LEITE, M. M. Retratos de família: leitura da fotografia histórica. 1. ed. São Paulo: EDUSP, 1993.

LIMA, G. F. da C. Educação Ambiental crítica: do socioambientalismo às sociedades sustentáveis. Educação e Pesquisa, São Paulo, v. 35, n. 1, p. 145-163, 2009.

MACEDO, R. L. G. et al. Pesquisas de percepção ambiental para o entendimento e direcionamento da conduta ecoturística em unidades de conservação. In: ECOUC, 2, CONGRESSO NACIONAL DE ECOTURISMO (CONECOTUR), 5, 2005, Rio de Janeiro. Anais eletrônicos... Rio de Janeiro: Universidade Estadual do Rio de Janeiro (UERJ), 2005. Disponível em: < http://www. physis.org.br/ecouc/Artigos/Artigo50.pdf >. Acesso em: 15 ago. 2012.

MARICATO, E. Brasil, cidades: alternativas para a crise urbana. 1 ed. Petrópolis, RJ: Vozes, 2001. 
MARTELLI, J. M. O uso da imagem na pesquisa educacional. In: REUNIÃO ANUAL DA ANPED. NOVO GOVERNO, NOVA POLÍTICA. O PAPEL HISTÓRICO DA ANPED NA PRODUÇÃO DE POLÍTICAS EDUCACIONAIS, 26, 2003, Poços de Caldas. Anais eletrônicos... Poços de Caldas, 2003. 1 CD-ROM.

MENDES, A. C. M.; NOBRE, I. de M. A fotografia na Educação Ambiental: reflexões sobre uma ação extensionista unindo educação e comunicação. In: CONGRESSO BRASILEIRO DE CIÊNCIAS DA COMUNICAÇÃO - INTERCOM - SOCIEDADE BRASILEIRA DE ESTUDOS INTERDISCIPLINARES DA COMUNICAÇÃO, 31, 2008, Natal, RN. Anais eletrônicos... Natal: UFRN, 2008. Disponível em: <mmw.intercom.org.br/papers/nacionais/2008/.../R3-2067-1. pdf>. Acesso em: 23 ago. 2012.

MINAYO, M. C. de S. O desafio da pesquisa social. In: MINAYO, M. C. de S. (Org.). Pesquisa social: teoria, método e criatividade. 27. ed. Petrópolis, RJ: Vozes, 2008. p. 09-29.

MORAES, R. Mergulhos discursivos: análise textual qualitativa entendida como um processo integrado de aprender e inferir discursos. In: GALIAZZI, M. do C.; FREITAS, J. V. de (Orgs.). Metodologias emergentes de pesquisa em educaşão ambiental. 2. ed. Ijuí: Unijuí, 2007. p. 85-114.

MORAES, R.; GALIAZZI, M. do C. Análise textual discursiva. Ijuí: Unijuí, 2011.

MUCELIN, C. A.; BELLINI, M. Lixo e impactos ambientais perceptíveis no ecossistema urbano. Sociedade \& Natureza, Uberlândia, v. 20, n. 1, p. 111-124, 2008.

RICHTER, L.; LOPES, G. M. do N.; FREITAS, D. S. Currículo, Formação de professores e uso de imagens no ensino. In: SEMINÁRIO NACIONAL DE FILOSOFIA E EDUCAÇÃO, 2, 2006, Santa Maria, RS. Anais eletrônicos... Santa Maria: Editora da UFSM, 2006. Disponível em: <http:// www.ufsm.br/gpforma/2senafe/ e5.htm>. Acesso em: 18 ago. 2012.

SACHS, I. Repensando o crescimento econômico e o progresso social: o âmbito da política. In: ARBIX, G.; ZILBOVICIUS, M.; ABRAMOVAY, R. (Orgs.). Razões e fições do desenvolvimento. São Paulo: UNESP; EDUSP, 2001. p. 155-163.

SANTANA, V. R. Questões socioambientais no ensino de Ciências: superando visões naturalistas no ensino fundamental. 2008. 151f. Dissertação (Mestrado em Ensino de Ciências). Universidade de Brasília, Brasília, 2008.

SILVA, A. J. P. et al. Ocupação humana como principal fator de degradação ambiental da região leste do rio Anil. In: CONGRESSO DE PESQUISA E INOVAÇÃO DA REDE NORTE E NORDESTE DE EDUCAÇÃO TECNOLÓGICA, 4, 2009, Belém. Anais Eletrônicos... Disponível em: $<$ http://www.connepi2009.ifpa.edu.br/connepi-anais/artigos/47_1324_1775.pdf>. Acesso em: 29 jul. 2012.

SILVA, L. S.; TRAVASSOS, L. Problemas ambientais urbanos: desafios para a elaboração de políticas públicas integradas. Cadernos Metrópole, São Paulo, n. 19, p. 27-47, 2008.

SOARES, B. E. C.; NAVARRO, M. A.; FERREIRA, A. P. Desenvolvimento sustentado e consciência ambiental: natureza, sociedade e racionalidade. Ciências \& Cognição, Rio de Janeiro, v. 2, p. 42-49, 2004.

STRIEDER, R. B. Abordagem CTS e ensino médio: espaços de articulação. 2008. 236 f. Dissertação (Mestrado). Instituto de Física - Departamento de Física Experimental, Universidade de São Paulo, São Paulo, 2008.

TAVARES, C. M. S.; BRANDÃO, C. M. M.; SCHMIDT, E. B. Estética e educação ambiental no paradigma da complexidade. Pesquisa em Educação Ambiental, São Carlos, São Paulo, v. 4, n. 1, p. 177-193, 2009.

TOZONI-REIS, M. F. de C. Formação dos educadores ambientais e paradigmas em transição. Ciência \& Educação, Bauru, v. 8, n.1, p. 83-96, 2002.

UHMANN, R. I. M. Educação ambiental como tema transversal na educação básica. In: GÜLLICH, R. I. da C. (Org.). Didática das Ciências. Curitiba: Prisma, 2013. p. 237-258

UNESCO. Década da Educação das Nações Unidas para um Desenvolvimento Sustentável, 2005-2014: Documento final do esquema internacional de implementação. Brasília: UNESCO, 2005.

VASCONCELOS, E. R. de; FREITAS, N. M. da S. O paradigma da sustentabilidade e a abordagem CTS: mediações para o ensino de ciências. AMAZÔNLA - Revista de Educação em Ciências e Matemá- 
ticas, Belém, v. 9, n. 17, p. 89-108, 2012.

VECCHIATTI, K. Três fases rumo ao desenvolvimento sustentável: do reducionismo à valorização da cultura. São Paulo em Perspectiva, São Paulo, v. 18, n. 3, p. 90-95, 2004.

VEIGA, J. E. da. Desenvolvimento sustentável: O desafio do século XXI. Rio de Janeiro: Garamond, 2008.

VILCHES, A.; GIL-PÉREZ, D. Emergencia planetaria: necesidad de um planteamiento global. Educatio Siglo XXI, España, n. 25, p. 19-50, 2007.

WUNDER, A. LAGANÁ, H. Dialogando sobre fotografia e ensino de Ciências. In: ROSA, M. I. P. (Orgs.). Formar: encontros e trajetórias com professores de Ciências. São Paulo: Escrituras Editora, 2005. p. 143-156.

ZIBETTI, D. W. Seguro agrícola e desenvolvimento sustentável. Curitiba: Juruá, 2006. 